\title{
Research on Enhancing the Mathematical Curriculum Test Scores of College Students
}

\author{
Qing-jian Zhou, Jia Jiao* \\ College of Science, Dalian Nationalities University, Dalian, Liaoning, China
}

\begin{abstract}
This paper focus on enhancing the mathematical curriculum test scores of college students. According to the teaching experience in college mathematics teaching for many years, the writer research on how to improve the mathematical curriculum test scores of college students, give some solutions and suggestions, and hope to provide some help to resolve the problem.
\end{abstract}

Keywords — mathematical curriculum, test scores, college student

\section{提高高校学生数学类课程成绩的方法探讨}

\author{
周庆健 焦佳* \\ 大连民族学院理学院, 大连, 辽宁, 中国
}

摘 要 本文根据笔者从事高校数学教学的多年教学经历, 对提高学生数学类课程成绩的问题进行了探讨, 给出了一些解决方法和 建议, 希望能对此问题的解决提供一些帮助。

关键词 数学类课程, 考试成绩, 大学生

\section{1. 引言}

高等数学、线性代数和概率论与数理统计是目前我国 高校课程设置体系中最常见的三科数学类公共基础课程。 数学类课程作为高等学校的重要理论基础课, 不仅是培养学 生逻辑思维能力和文化素养的重要手段, 也是学习后续专 业课程的重要基础, 更是衡量高校人才培养质量的重要标 准。目前, 在高校学习中, 许多学生, 尤其是文科学生对 数学类课程比较畏惧, 可谓闻 “数”色变, 出现考试成绩不 理想, 甚至很多同学“挂科”等现象。这是高校高等教育中 要正确面对和急需解决的重要课题。关于这个问题, 众多 学者做了大量研究 [1-6]。但是, 其中还存在一些问题需要 进一步研究和解决。本文主要以笔者所在大学一大连民族 学院为例, 根据自己 10 多年从事一线数学教学的工作经验, 对如何提高高校学生数学类课程成绩这一问题作出分析, 并给出一些解决方法和建议, 希望能够抛砖引玉, 与广大 教学工作者和管理工作者共同探讨。

\section{2. 目前数学类课程教学中存在的主要问题}

\section{1 教师感觉不好教}

数学类课程是大学文理科的基础课, 担负着培养学生 基本技能、基本能力和思维方法的重任。然而, 现在的实 际情况是, 学生的学习基础差、参差不齐、学习积极性低、 学习方法不得当和考试通过率低。尽管高校做了很多努力, 如课程与教材的改革、教学方式与教学评价的改革等, 但 现实仍不理想。很多教师感觉数学类课程不好教, 怎么教 都有学生学不懂等等。

\section{2 学生对数学类课程比较畏惧, 成绩不理想}

数学是一门承接性很强的课程, 对基础知识的要求比 较高, 如果不能将高中以前的数学基础打牢, 必定会影响 大学阶段的数学学习和成绩, 学生一旦跟不上正常的学习 进度, 心理就会出现波动, 形成对数学类课程的畏惧, 讨

辽宁省教育厅科研项目 (资助号: L2014549), 中央高校自主科研基金 (资助号: DC201502050409), 大连民族学院教改项目: 提高 我校学生数学类课程成绩的研究与实践 (资助号: 42), 大连民族学院 2014 年度本科教学质量与教学改革工程项目 (资助号: 003-2014600501) 
厌甚至是回避。

经历了多年的数学学习, 每个学生都有自己对数学类 课程的学习态度。这是一种相对稳定的、内在的心理状态。 它包含认知、情感和行为倾向三种成分。由于每个学生的 数学教育成长的背景不同, 再加上智力上的个体差异, 从 而形成了不同的数学态度, 良好的数学态度会促进数学类 课程的学习。反之, 不良的数学态度肯定会妨碍数学的学 习。如有的学生对数学的感觉就是“数学太难学了”、“数学 烦死人了, 我恨数学!”、“数学好恐怖, 我一见数学就头 疼”。最终导致数学类课程的成绩不理想。

\section{3 影响学生对后继课程的学习、考研甚至是正常毕业}

数学类课程是重要的基础课程, 很多专业的专业课程 需要以其作为基础, 比如计算机、通信, 经济学专业等等, 如果这三科没有学好, 那么会影响很多同学学习后继的专 业课程, 比如傅里叶变换, 微观经济学等等。

另外由于这三科数学课程是考研数学的主要内容, 所 以很多学生因为数学类课程成绩不好, 导致没有信心考研, 甚至没有勇气去报考。

而且根据多年的调查发现, 很多学生因为这三科数学 类课程考试不及格, 到毕业之前未能拿到学分, 从而影响 他们的正常毕业, 只能继续念“大五”。

\section{3. 原因分析}

由于出现了以上诸多的问题, 笔者结合自己多年的教 学经验, 并作大量调研, 总结出原因如下:

\section{1 扩招造成大学入学门槛降低, 许多学生数学基础不好。}

自上世纪九十年代起, 我国的高等教育已经逐步进入 大众化教育阶段。据统计, 我国高等教育在校学生规模已 居世界第一。由于大学扩招, 大学的入学门槛相比以前有 了一定降低, 很多学生的入学成绩较以往有一定的退步。

按照美国教育社会学家马丁. 特罗的观点来看, 中国高等教 育已经由精英化进入大众化教育阶段。

以大连民族学院为例, 学生有 56 个民族。许多来自贫 困地区(包括民族地区)的学生, 尤其是有一定比例的来自民 族地区的少数民族学生。学生的入学分数相差较大, 呈现 两极分化。许多学生的数学基础参差不齐, 有的相当差。 高中的数学知识掌握的不好, 举例来说, 有的学生连三角 函数这样的基本概念都没理解和掌握, 以这样的基础来学 大学数学, 确实勉为其难。
3.2 学生对数学的认识不够, 心理恐惧, 学习方法不得当

很多学生不能正确认识数学的重要性, 没有科学和正 确的数学观, 一见数学就头疼, 对数学形成的认识是畏惧, 导致丧失学习数学的兴趣。

另外在应试教育的高压下, 多年的数学学习, 让学生 习惯了课堂上教师大信息量的灌输, 课下学生们在浩瀚无 边的题海中苦游; 学生很少主动思考, 只知道做题; 学生 很少提问题, 只知道回答问题; 学生很少自己安排学习, 只知道遵照教师的安排学习。这种学习方式让学生误解了 数学学习。

在国外大学, 学生的学习自主性比国内的要强很多。 学生每一天的大学生活, 就像高考, 紧张但合理紧凑。比 如加拿大的考试及格线是 50 分, 按理说者是很低的界, 但 不同的是国内的大学只要期末考试过 60 分就算通过。比如 在加拿大, 平时每星期一次的作业 (一门课的一次作业在 3 5 小时之内完成), 每一次的小型测验、期中考试, 都会算在 期末的总成绩里面, 当然期末考试的比例占得要大一些。 具体举例如下: 作业占 $15 \%$, 测试占 20\%, 期中考试占 $25 \%$, 期末考试占 $40 \%$, 所以平时的每一项工作都要认真地去做, 才不会影响到最终的课程成绩。如果达不到 50 分, 只能重 新学习, 这样既耽误时间, 又浪费学费。反观国内的大学 教育, 学生在平时的学习过程中非常轻松, 很多学生基本 上平时可以不怎么学习, 临到期末考试, 鳌夜苦战, 可能 就通过了最后的期末考试。

所以, 诸多这些不得当的学习方法是很难适应大学里 数学类课程的学习, 很难获得好的学习成绩的。

\section{3 教师的教学效果需提高}

目前, 数学类课程的教学模式一般都是教师一言堂, 填鸭式, 重教不重学, 以讲授数学知识为主, 课时紧, 任 务重, 而且一般都是大班授课, 每班 100 多人。对学生学 习相应知识的掌握情况不了解, 教学效果不甚理想。

\section{4. 解决方法和建议}

4.1 学生应增加数学学习的自信心, 加强自主性学习, 调整 心态, 正确面对考试

作为学习的主体, 在数学类课程的学习过程中, 学生 肯定会遇到许多困难和问题, 学生要有克服困难的勇气和 信心, 学习中遇到问题要及时找老师或者同学解决, 千万 不能让问题累积, 形成恶性循环, 而是要在老师的引导下, 增加自信心, 寻求解决问题的办法, 培养分析问题和解决 问题的能力。 
并且在考试中, 自信心也很重要。面对数学考卷, 内 心习惯性的恐惧感会导致思维混乱和间歇性遗忘, 以这样 的状态应对考试, 自然无法考出自己的平时的真实学习水 平, 这也是许多学生经常在考试中发挥失常的重要原因。 所以自信心对数学类课程的学习非常重要, 不仅会在平时 的学习中对学习心态和学习效率产生重要影响, 还会在考 试过程中直接影响考试水平的发挥。

随着高等学校的不断扩招, 还有科学发展的突飞猛进, 要求学生学习的知识越来越多, 高校里数学类课程的学时 一减再减, 比如高等数学一般都由原来的 192 课时缩减到 160 课时, 线性代数和概率论与数理统计一般都由原来的 48 课时缩减为 32 课时。使得教师在课堂上无法像以前那样 完成教学任务。因此, 学生应加强自主性学习, 学生通过 学生个体、小组团体、班级整体、师生全体等各个层面的 自主探索与讨沦交流, 研究式地学习而获得知识、锻炼思 维、提高能力。而在教师的引导下, 学生应加强自读书、 自质疑、自求索。在自主学习过程中把握重点, 找出难点。 还可以与同学积极展开讨论, 共同探讨学习中的问题, 获 得科学知识。

4.2 教师应以身立教, 善于引导, 增加师生交流, 因材施教, 提高教学效果。

教师应以身立教, 严于律己, 以身作则。“教书者, 必 先强己; 与人者, 必先律己。”教师严于律己, 要求学生做 到的, 自己首先做到。学生就会模仿教师, 严格要求自己, 在学习血红提高自律性。正如德国教育学家第斯多惠所说: “教育的艺术不在于传授知识, 而在于激励、唤醒和鼓舞。” 所以教师在平时的教学活动中, 善于引导学生发现问题、 思考问题和解决问题。

在教学中, 教师要提高教学效率。课堂效率的提高与 教和学有密切的关联。教指的是教师教学行为和内容, 提 高教学质量关键在于教师的知识水平和表达能力。绝大多 数教师的整体知识水平是得到认可的, 但有些具体教学行 为值得注意和提高。比如备课和板书。备课是教师教学中 的一个重要环节, 备课的质量直接影响到教学效果。同时 在教学过程, 与学生进行直接信息交流的是板书和口述, 口述大多教师都能做得很好, 但疏于板书, 这种教学行为 忽略了一个重要因素: 学生上课时的注意力。据生理学家 研究发现, 青春期的学生每节课只能够集中注意力 30 分钟 左右。在这 30 分钟时间里, 大多数学生都有走神的情况, 从而造成学生对老师讲解的某些部分内容没听进去, 降低 了课堂效率。而如果教师在上课时能够完整地对讲解内容 进行板书, 学生即使出现课堂上走神, 也可以通过快速测
览教师的板书, 将走神时“失听”的内容加以捡回。因此, 教师要提高课堂效率, 必须积极探索适合于学生学习的教 学方法, 做到多提问、多归纳、多总结。

另外数学教师要加强课下与学生的交流与访谈。教师 不能把工作仅仅停留在课堂上, 课下的交流与访谈是不可 或缺的, 在此过程中一方面能了解他们的数学态度, 另一 方面也能改变他们的数学态度。根据学生的不同实际情况, 因材施教, 提高教学效果。

4.3 辅导员应加强学风建设, 增加对学生的教学指导

“优良校风, 学风对学生起着潜移默化的作用, 是保证 教学质量的前提。高等学校要将学风建设作为教学工作的 一项重要内容来抓。

学校要教育学生从思想上重视数学学习的重要性。定 期由辅导员召开学生座谈会, 提高学风建设。让学生从思 想上认识到学习素养的好坏, 直接影响到自己的成材和将 来的成材。好的学风可带动所有学生学习的主观积极性, 对提高学习成绩非常重要, 尤其是比较难学的数学类课程 更显必要。

大学教育是知识创新、传播和应用的主要基地, 也是 培养创新精神和创新人才的摇篮, 数学类课程作为基础课, 更是首当其冲, 所以, 辅导员有责任帮助学生转变学习方 式, 整治在应试教育中感染上的不良㽽疾, 使他们尽快适 应数学学习。有几个方面尤为重要:

（1）培养学生的自学能力。当今的人才的一个基本特 征就是自己会学习, 学会学习的重要标志就是具有较强的 自学能力。学生要培养自己的自学能力, 自主安排时间, 自主制定计划, 预习、章节小结与复习、学期的总复习等, 将对整个大学乃至终生的学习起到很大的作用。

(2) 培养学生的合作精神。数学学习是需要交流与合 作的, 学生之间的差异很大, 数学底子参差不齐的现象较 严重, 在没有分层次教学的条件下, 合作学习显得非常重 要, 所以, 辅导员要将班级分成学习小组, 制定计划, 互 帮互学, 分组时要特别考虑到教育发达地区与落后地区学 生的搭配, 对数学学习的弱势群体给予特别地关注。

(3) 教学管理部门进行教学模式的改革, 增加期中考 试, 取消补考, 加强重修

当今社会科技快速发展, 社会对不同专业的学生数学 要求不尽相同。对各行业来说, 既需要能较快接受新知识、 新技术, 并应用于本专业的工程技术型人才, 也需要进行 深入理论研究, 高新技术开发科学研究型人才。因此, 从 社会这一外界因素来讲, 对人才数学基础的要求也各不相 同。另外, 相当一部分同学有考研的数学要求, 考取研究 
生学生的数量既能代表高校的基础课和专业课的教学水 平, 又影响学校就业的数量和质量。因此, 高校要适应社 会的发展需要, 适当进行教学模式的改革, 因材施教, 提 高不同层次学生的数学学习能力。

同时高校管理部门要改进成绩的考核体系, 可实行期 末考试和平时考核相结合的评价方法, 并逐步加大平时考 核成绩, 特别是增加期中考试在总成绩中所占比例。可以 实行百分制、等级制、评语相结合的评分方法。通过各方 面的努力, 降低不及格率。

另外, 根据笔者的教学经验和同行交流, 强烈建议教 学管理部门取消补考和毕业前大补考, 让学生充分认识考 试的严肃性。如果学生得到的某科课程的成绩为不合格, 则该门课程必须进行重修。重修当然不是目的, 但可以激 发学生改进学习态度和方法, 获得相应知识。目前高校实施 的重修方法主要有三种: (1)单独开班重修,一般在周末上课; (2)跟班重修, 跟随下一年级班级上课; (3)自学重修, 自己 独自学习, 最后参加重修考试。根据调查, 笔者建议: 为 保证教学质量, 最好的方法还是开班重修。

\section{5. 结论}

本文结合笔者从事高校数学教学的多年教学经历, 对 提高数学类课程成绩的问题进行了探讨, 给出了一些解决 方法和建议, 希望能对此问题的解决提供一些帮助。

\section{参考文献(References)}

[1] S. C. WANG and L. D. WANG, "Studies on Current Situation of Freshmen's Attitudes Towards Mathematics in Ethnic Colleges and Universities," Journal of mathematics education, vol. 23, no. 5, pp. 69-72, 2014.

[2] M. Zhou, "Research on mathematical score of students in senior high schoo," Modern Shopping, no. 697, pp.208-209, 2012.

[3] S. C. WANG and Q. Liu, "First class in advanced mathematic is the begin to the translation of mathematical concept of college studies," Teaching and Education. Higher education BBS, no. 10, pp. 100-101, 2012.

[4] L. Yang, "Effective research on mathematical score of students in junior high school," Research on teaching, no.153, pp.54-65, 2012.

[5] Z. F. Hou and S. L. Hu, "Research on Make-up examination and Reset of college students," Science and technology in western China.Education and Talent, vol. 07, no.32, pp.89-90, 2008.

[6] Y. Zhang, L. D. Wang and M. Liu, "Exploration of gradational teaching in advanced mathematics of nationalities university," Journal of Dalian Nationalities University, vol. 10, no. 3, pp. 274-279, 2008. 